\title{
Iwona Dronia
}

Wyższa Szkoła Zarzadzania Marketingowego i Jezykón

Obcych Katowice

\section{NIEPELNOSPRAWNOŚĆ I SPECJALNE POTRZEBY EDUKACYJNE W ŚWIETLE POLSKIEJ I BRYTYJSKIEJ POPRAWNOŚCI POLITYCZNEJ}

\author{
Disability and Special Education Needs in the light \\ of Polish and British Political Correctness
}

\begin{abstract}
The main goal of this article is to describe the legal status and situation of disabled learners in Poland, the UK and in other European countries. The author wishes to analyze whether the trends advocated by the principles of Political Correctness (PC) have influenced the language used in the educational context, and, in particular, towards students of special education needs (SEN). The article attempts to demonstrate that neither English nor Polish are sufficiently polite in terms of describing, categorizing, evaluating or naming all the learners, who, owing to their mental or physical impairment, have Special Educational Needs.
\end{abstract}

\section{Wprowadzenie}

Celem niniejszego artykułu jest przedstawienie zarysu polityki edukacyjnej Polski, Wielkiej Brytanii i innych krajów europejskich w stosunku do osób reprezentujacych specjalne potrzeby edukacyjne. Dodatkowym celem jest dokonanie krótkiej analizy języka polskiego i angielskiego związanego z zagadnieniem niepełnosprawności. Analiza ta oparta jest o założenia norm poprawności politycznej i szeroko pojętej grzeczności językowej. 


\section{Sytuacja prawna osób reprezentujących specjalne potrzeby eduka- cyjne w Polsce}

Zgodnie z obowiązującymi przepisami prawa oświatowego (Ustawa z dnia 7 września 1991 r. o systemie oświaty (tekst jednolity Dz. U. z 1996 r., Nr 67, poz. 329 z późniejszymi zmianami) kształceniem specjalnym obejmuje się dzieci i młodzież z zaburzeniami i odchyleniami rozwojowymi, wymagające stosowania specjalnej organizacji nauki i metod pracy. W zależności od rodzaju oraz stopnia zaburzeń i odchyleń dzieciom i młodzieży, o których mowa w ust. 1, organizuje się formy kształcenia i wychowania, które stosownie do potrzeb umożliwiaja naukę w dostępnym dla nich zakresie, usprawnianie zaburzonych funkcji, rewalidację i resocjalizację oraz zapewniają specjalistyczną pomoc i opiekę (Art. 71b). Za osoby niepełnosprawne uznaje się:

1. osoby przewlekle chore - cierpiace np. na długotrwałe schorzenia narządów ruchu, cukrzycę i epilepsję;

2. osoby niedowidzace - o wadzie wzroku przekraczającej + lub -5 dioptrii (wady te to z reguły wady refrakcji, a więc krótkowzroczność, nadwzroczność lub astygmatyzm);

3. osoby niedosłyszacce - o obniżeniu progu słyszalności i ubytku słuchu o co najmniej 20-40 decybeli;

4. osoby niepełnosprawne umysłowo. Wśród tej kategorii wyróżnić należy cztery dodatkowe podkategorie opóźnienia:

- lekkie

- umiarkowane

- znaczne

- głębokie

Opóźnienie w rozwoju intelektualnym obrazowane jest skalą Wechslera, determinująca iloraz inteligencji i stopień niepełnosprawności.

\begin{tabular}{|c|c|c|}
\hline $\begin{array}{l}\text { Ilorazy inteligencji } \\
\text { w skali D.Wechslera }\end{array}$ & Stopień rozwoju umysłowego & Klasyfikacja kliniczna \\
\hline powyżej 146 & bardzo wysoka inteligencja & \\
\hline $131-146$ & wysoka inteligencja & \multirow{3}{*}{$\begin{array}{l}\text { prawidłowy rozwój } \\
\text { umysłowy }\end{array}$} \\
\hline $116-130$ & inteligencja powyżej przeciętnej & \\
\hline $85-115$ & przeciętna inteligencja & \\
\hline $70-84$ & inteligencja niższa niż przeciętna & pogranicze normy \\
\hline $55-69$ & upośledzenie w stopniu lekkim & lżejsze upośledzenie \\
\hline $40-54$ & upośledzenie stopniu umiarkowanym & \multirow{3}{*}{ głębsze upośledzenie } \\
\hline-39 & upośledzenie w stopniu znacznym & \\
\hline & upośledzenie w stopniu głębokim & \\
\hline
\end{tabular}

Tabela 1. Iloraz inteligencji i stopień rozwoju umysłowego (Krasowicz-Kupis, G. i K. Wiejak, 2008:20). 
5. dzieci autystyczne - charakteryzujące się złożonymi zaburzeniami rozwojowymi uwidocznionymi w trzech sferach - komunikacji, funkcjonowaniu społecznym i prezentowanych zachowaniach.

Uczniowie niepełnosprawni otrzymują orzeczenie poradni psychologiczno-pedagogicznej o potrzebie kształcenia specjalnego, w którym zawarte są zalecenia dotyczące form wspierania ucznia niepełnosprawnego realizującego obowiązek szkolny w szkole ogólnodostępnej. Szkoła zobowiązana jest zorganizować dla tych uczniów dodatkowe zajęcia rewalidacyjne dostosowane do ich specjalnych potrzeb edukacyjnych. Zajęcia te moga mieć charakter indywidualny bądź grupowy (wynika to z indywidualnych programów poszczególnych uczniów).

\section{Kształcenie uczniów ze specjalnymi potrzebami w krajach Unii Europejskiej}

Kształcenie uczniów ze specjalnymi potrzebami w krajach Unii Europejskiej może przybierać różne formy - za w.w. grupę dzieci uznaje się jednak te, które maja upośledzenie fizyczne, sensoryczne (np. głuchota lub problemy ze wzrokiem), poważne problemy w nauce lub problemy emocjonalne. W zależności od polityki prowadzonej w stosunku do tej grupy kraje europejskie można podzielić na trzy grupy. Mazińska (2004: 44-46) przedstawia następujący podział:

kraje jednej ścię̇ki - w których następuje integracja prawie wszystkich dzieci w głównym nurcie edukacji. Szkoły tego typu mają zapewnione różne formy pomocy w zakresie odpowiednio przygotowanej kadry nauczycielskiej, materiałów dydaktycznych i sprzętu. Takie podejście przyjęto np. w Grecji, Włoszech, Portugalii czy Norwegii; w tych krajach odsetek uczniów uczęszczających do specjalnych (odrębnych) klas lub szkół wynosi poniżej 1\%.

kraje dwóch ścieżek - z dwoma różnymi systemami edukacji, funkcjonującymi na podstawie odrębnych przepisów dotyczących głównego nurtu oraz szkolnictwa specjalnego. Taki wyodrębniony sektor nauczania specjalnego działa np. w Belgii, Holandii lub Rumunii.

kraje wielu ściejek - w których propagowane jest wielokierunkowe podejście do integracji uczniów ze specjalnymi potrzebami edukacyjnymi. Kraje te popularyzują ideę łączenia rozwiązań typowych dla obu typów szkół - ogólnie dostępnych i specjalnych, np. specjalne zajęcia dla różnych grup łącznie (w pełnym lub niepełnym wymiarze czasu) lub różne formy współpracy międzyszkolnej, włącznie z wymianą nauczycieli i uczniów ze szkół zwykłych i specjalnych. Takie „eklektyczne” podejście stosowane jest np. w Niemczech, Francji, Wlk Brytanii, Polsce, na Litwie, Słowacji, w Słowenii i Węgrzech. W tych krajach odsetek uczniów w szkołach specjalnych wynosi 1-5\%. Uczniowie kształceni są w taki sam sposób, różni ich jedynie czas kształcenia obowiązkowego, z reguły dłuższy w szkołach specjalnych. W większości tych krajów nauczyciele otrzymują wsparcie pedagogiczne - zatrudnieni specjaliści wspomagają i doradzają nauczycielowi prowadzącemu klasę (ibid.). 
3.1. Sytuacja osób ze specjalnymi potrzebami edukacyjnymi w Wielkiej Brytanii

Sytuacja osób ze specjalnymi potrzebami edukacyjnymi normowana jest w Wielkiej Brytanii przez kilka istotnych rozporządzeń, z których wymienić należy The Disability and Discrimination Act z 1995 roku, Children Act (1989), The Education Act (1996) czy też Special Education Needs Code of Practice z 2001 roku. Właśnie ten ostatni dokument (2001: 6-7) charakteryzuje w sposób szczegółowy obszary, w których mogą wystapić deficyty:

\section{A. Cognition and Learning Needs}

- Specific Learning Difficulty (SpLD)

- Moderate Learning Difficulty (MLD)

- Severe Learning Difficulty (SLD)

- Profound and Multiple Learning Difficulty (PMLD)

B. Behaviour, Emotional and Social Development Needs

- Behaviour, Emotional and Social Difficulty (BESD)

\section{Communication and Interaction Needs}

- Speech, language and Communication Needs (SLCN)

- Autistic Spectrum Disorder (ASD)

\section{Sensory and/or Physical Needs}

- Visual Impairment (VI)

- Hearing Impairment (HI)

- Multi-Sensory Impairment (MSI)

- Physical Disability (PD)

Należy tutaj nadmienić, iż pojęcie 'specjalnych potrzeb' ma w Wielkiej Brytanii zdecydowanie szersze spektrum. Modny obecnie slogan inclusion (włączenie) nadaje nowy wymiar podejściu do integracji. Z drugiej strony, mnogość ustaw i rozporządzeń pozwala na zdecydowanie częstsze użycie określenia „uczeń specjalny”. McMinn (2002: 4) przedstawia podział zaburzeń mowy i rozwoju języka, który za osoby ze specjalnymi potrzebami uznaje także te, cierpiące np. na dysleksję, ADD czy też ADHD.

4. Poprawność polityczna i jej elementy w języku adresowanym do uczniów ze specjalnymi potrzebami edukacyjnymi - charakterystyka materiału badawczego.

W ostatnich latach sytuacja w całej Europie drastycznie się zmienia, również z powodu propagowania zasad poprawności politycznej w sferze zachowań, uwarunkowań prawnych, rozwiązań kulturalno-socjalnych czy też językowych. Zauważyć można na 
przykład, szeroko zakrojoną tendencję do zmian istniejących ,szkół specjalnych” na te ,z oddziałami integracyjnymi”. Mówi się również o zajęciach kompensacyjnych, rewalidacyjnych lub wyrównawczych, a klasy nazywa integracyjnymi. Słowo ,specjalny” zyskuje coraz bardziej pejoratywne znaczenie. Druga część tego artykułu aspiruje więc do przedstawienia pewnych zagadnień związanych z Poprawnością Polityczną (PP) i jej elementów w języku adresowanym do uczniów ze specjalnymi potrzebami edukacyjnymi. Część empiryczna ilustruje badania prowadzone na przełomie pięciu lat (2003-2008). Podstawowym celem przeprowadzonych badań było zgromadzenie wyrażeń i określeń używanych w stosunku do osób reprezentujących pewne deficyty fizyczne lub intelektualne. Trzymilionowy korpus słów angielsko-polskich pozwolił na wyodrębnienie ponad dwóch tysięcy wyrażeń używanych w kontekście edukacyjnym. Zebrane przykłady, pochodzące z bardzo zróżnicowanych źródeł, takich jak, np. encyklopedie, słowniki, opracowania naukowe, artykuły w prasie specjalistycznej, ale również analiza dokumentacji psychologiczno-neurologicznej studium przypadku, wyniki analiz kwestionariuszy, rozprowadzonych pomiędzy angielskich i polskich nauczycieli i psychologów, mających regularny kontakt z tą specyficzną grupą uczniów, ocenione są pod kątem stworzonych przez autorkę 'reguł' poprawności politycznej, zaklasyfikowane są jako pozytywne, a więc będące w zgodzie z normami grzeczności językowej, lub negatywne, stanowiące atak na Twarz rozmówcy (Marcjanik, 2001, 2007; Kita, 2005; Grodziński, 1980).

Stojąc na stanowisku, iż poprawne politycznie zachowanie, to przede wszystkim takie, które ma na celu szacunek rozmówcy, zachowanie zgodne z założeniami etykiety i atmosfery grzeczności językowej, które nie propaguje agresji językowej oraz zachowań nieodpowiednich dla ogólnie przyjętych norm 'dobrego wychowania', a także oparte jest o teorię ustanowioną przez Allana i Burridge’a (1991: 31) „kryterium uprzejmości klasy średniej" polegającą na jak najczęstszym stosowaniu eufemizmów, właśnie takie 'normy' uznane zostały przez autorkę za pozytywne i nieobraźliwe.

\subsection{Nazewnictwo stosowane w kontekście edukacyjnym}

Analiza zgromadzonego materiału badawczego pozwoliła na wyodrębnienie w obydwu językach kilku grup leksykalnych: wyrażeń stosowanych najczęściej, najrzadziej (często ze względu na swą enigmatyczność), określeń typowych dla kontekstu edukacyjnego, języka medycznego, eufemizmów, idiomów, nowoutworzonych wyrażeń i peryfraz, wulgaryzmów (niestety bardzo częstych zarówno w korpusie polskim, jak i angielskim), wyrażeń wskazujących na ograniczenia w życiu. Ze względu na ogromną liczbę przykładów, dalsza część artykułu przedstawi jedynie kilka grup leksykalnych.

\subsubsection{Wyrażenia angielskie stosowane w kontekście szkolnym:}

study Center (in the middle school) and Academic Workshop (in the high school); mixed ability classes, special classes, mainstream classes ale także remedial classes and groups, remedial assistance and work; support classes in regular schools; normal or special schools, (ostatni termin stosowany jest rzadko i nadal budzi pewne zastrzeżenia). 


\subsection{Wyrażenia poprawne politycznie związane $\mathrm{z}$ grupą specjalnych potrzeb edukacyjnych (Special Educational Needs):}

intellectually-challenged, differently-abled; 'able bodied', otherly-abled, uniquely abled misunderstood kids; high functioning children; people with disabilities (zamiast disabled people); inconvenienced; challenged (e.g. aurally challenged, cerebrally challenged, linguistically challenged, orthographically challenged, verbalby challenged); konstrukcja person with (such as person with a disability, person who is blind, peoplel person with differing abilities, people with mild disabilities, person in a wheelchair, a lame person); person/people with seeing difficulties, people with differing/learning disabilities, children with low/very low IQs; with different abilities;

have difficulty/trouble/problems with e.g. have trouble regulating their behaviour (used about ADHD pupils), have difficulty in forging ahead, children with problems with abstract ideas, may have difficulty in the processing of information and in communicating what they know or understand (used about dyspraxia),

good/poor/weak at..., etc:: poor at organizing their thoughts and time or slower in grasping new work (used about low IQs), poor understanding of tense, pronouns and syntax, poor spatial ability (used about dyslexia), limited/poor communication skills (used about Asperger's syndrome and autism), high/low/weak ability children.

less, such as less academic, less gifted, less prepared but also less favoured - (a derogatory term used about less intelligent people),

terminologia medyczna (Down's syndrome, Down's people or Down's syndrome patients zamiast mongolism, neurobiological/ mental disorder, moderate/severe learning difficulties, poor gross/fine motor control (used about dyspraxia), chronic impairment, children with minimal numerical skills and time concepts, developmental disabilities,

children with low/very low IQs, retarded in achievement, children with lower developmental stage of conceptualization, neurological immaturity, underdeveloped imaginative skills (used about ADD and autism), children with language delays

eufemizmy i peryfrazy, i.e. hard of hearing (deaf), easily distracted and daydreaming, emotionallydisturbed or disruptive children (ADD or ADHD), clumsy-child syndrome (dyspraxia), learning differences (SEN students), bidden handicap (Autism and Asperger's syndrome), students with learning challenges or those who have not been able to perform to their capabilities (SEN learners), vague language, as it seems, apparently, it gives the impression..., prima facie, at first sight, operating at conceptual levels below their chronological ages/ below their typically developing peers., or having the age of/ not behaving as a child at his/her age/, having a mental age of ...., unable to cope with the work of their age group,

\subsection{Wyrażenia niepoprawne politycznie w języku angielskim}

\section{Zmiana semantyczna - pejoryzacja}

disabled; (physically) handicapped and 'cap in hand'; mentally/ physically retarded, deaf and its diminutive form 'deafies', stone deaf, out and out blind, cripple and crips, physically different, invalid; (physically) abnormal; backwards, mentally deficient, educationally / academically subnormal 


\section{Wyrażenia wskazujące na ograniczenia w życiu}

afflicted by, suffering from (e.g. mental alienation); a sufferer/victim of ...;confined to e.g. a wheelchair, wheelchair-bound, touched by, crippled by, stricken by

\section{Niepoprawne wyrażenia/ terminy medyczne}

mongolism, mongol, (zamiast tego: Down's syndrome, Down's syndrome patients or Down's people); imbecile, paralytic, cretin, LDs (używany jako zniewaga), defective, deformed, mad, crasy, insane, abnormal, spastic, mentally deranged/disordered; lunatic (asylum);extreme behaviour disorders; schizophrenia (zamiast tego: Kraepelin's syndrome); Leprosy (zamiast tego: Hansen's disease)

\section{Nowoutworzone wyrażenia}

\begin{tabular}{|l|l|}
\hline Przykłady: & Użycie \\
\hline mADDening child & ADD \\
\hline $\begin{array}{c}\text { people who run into difficulties } \\
\text { another new bandwagon }\end{array}$ & ADD, ADHD \\
\hline thrill-seeking people & ADD/ADHD \\
\hline moral defectiveness & ADHD \\
\hline little monsters & ADHD \\
\hline constant failure child & ADHD children \\
\hline less fortunate students & learning disabilities \\
\hline less favoured students & SEN learners \\
\hline unfortunate children & SEN learners \\
\hline & SEN learners \\
\hline
\end{tabular}

Tabela 2. Niepoprawne politycznie wyrażenia w stosunku do osób ze specjalnymi potrzebami edukacyjnymi.

\subsection{Nowo utworzone wyrażenia, peryfrazy:}

\begin{tabular}{|l|l|l|}
\hline Przykład & $\begin{array}{l}\text { Użyty w sto- } \\
\text { sunku do: } \\
\text { their career have such a } \\
\text { meandering course }\end{array}$ & ADD/ADHD \\
\hline willful children & $\begin{array}{l}\text { Flanagan and Strong, 2005, } \\
\text { book cover }\end{array}$ \\
\hline big-picture people & ADD/ADHD & Flanagan and Strong, 2005:17 \\
\hline $\begin{array}{l}\text { driven by a motor (being } \\
\text { always on the go) }\end{array}$ & ADD/ADHD & Flanagan and Strong, 2005:34 \\
\hline misunderstood kids & ADD/ADHD & Flanagan and Strong, 2005:36 \\
\hline
\end{tabular}


Iwona Dronia

\begin{tabular}{|c|c|c|}
\hline $\begin{array}{l}\text { the children who walk in } \\
\text { the shadows }\end{array}$ & autism & $\begin{array}{l}\text { Brown in Waterhouse, } \\
2000: 326\end{array}$ \\
\hline aurally challenged & deaf & Rees, 1995: 3 \\
\hline buddy system & dyspraxia & Waterhouse, 2003 \\
\hline $\begin{array}{l}\text { exceptional and special } \\
\text { learners }\end{array}$ & $\begin{array}{l}\text { mentally } \\
\text { handicapped; } \\
\text { SEN learners }\end{array}$ & Rees, 1995:93 \\
\hline mentally confused & mentally ill & $\begin{array}{l}\text { Cambridge Advanced Learn- } \\
\text { er's Dictionary, } 2003\end{array}$ \\
\hline uniquely abled & $\begin{array}{l}\text { mentally re- } \\
\text { tarded }\end{array}$ & Rees, 1995: 138 \\
\hline university challenged & $\begin{array}{l}\text { mentally re- } \\
\text { tarded }\end{array}$ & Rees, 1995: 138 \\
\hline $\begin{array}{l}\text { physiologically disfren- } \\
\text { chised }\end{array}$ & $\begin{array}{l}\text { physically } \\
\text { handicapped }\end{array}$ & Rees, 1995:114-115 \\
\hline $\begin{array}{l}\text { Students who have diverse } \\
\text { learning needs }\end{array}$ & SEN learners & Smyth, B., 2005 \\
\hline $\begin{array}{l}\text { requiring education tai- } \\
\text { lored for their needs }\end{array}$ & SEN learners & www.marvelwood.org. \\
\hline under-performing pupils & SEN learners & www.tes.co.uk \\
\hline $\begin{array}{l}\text { exceptional families with } \\
\text { exceptional kids }\end{array}$ & $\begin{array}{l}\text { sensory } \\
\text { processing } \\
\text { disorder }\end{array}$ & www.ncbi.nlm.nih.gov \\
\hline
\end{tabular}

Tabela 3. Przykłady peryfraz.

\subsection{Niepoprawność polityczna w języku polskim}

\section{Wyrażenia idiomatyczne i eufemizmy}

ciemniak, ciemna masa, dziecko wojny genetycznej, nie umiejacy zliczyć do trzech, majacy kotal fisialfiola, nierówno pod sufitem, wybitnie zdolne ale nie potrafiace kochać, ma trudności z...., wykazuje mata aktywnośc/ qainteresowanie), (bardzo) stabo orientuje sie, występuja pewne nieprawidłowości

\section{Wyrażenia omowne ${ }^{2}$}

- Choroba Świętego Wita (epilepsja-padaczka)

\begin{tabular}{|l|l|}
\hline Kategoria gramatyczna & Przykład \\
\hline PERYFRAZY & choroba swiętego Wita \\
\hline EUFEMIZMY & najbardziej inteligentna forma antyzmu \\
\hline WYRAŻENIA IDIOMATYCZNE & ciemna masa, dziecko wojny genetycznej \\
\hline
\end{tabular}

2 nazwa zaczerpnięta ze Stownika Peryfraz. czyli wyrażeń omownych, Bańko, M., 2005. 
Niepełnosprawność i specjalne potrzeby edukacyjne w świetle polskiej i brytyjskiej...

\begin{tabular}{|l|l|}
\hline \hline RZECZOWNIKI & ciemniak \\
\hline RZECZOWNIKI Z PRZYDAWKAMI & ciemna masa \\
\hline OKSYMORONY & inteligentny autyzm \\
\hline
\end{tabular}

Tabela 4. Polskie przykłady peryfraz użytych w stosunku do osób reprezentujących specjalne potrzeby edukacyjne.

\section{Wyrażenia rzadkie i enigmatyczne:}

syndrom Pinokia; autystyczni psychopaci; biato-czarne dziecko (o syndromie Aspergera) uczeń trudny; wspaniali sprawni inaczej; tacy sami choć indywidualni, dzieci specjalnej troski; (o osobach ze specjalnymi potrzebami)

dzieci nowych czasów; dzieci indygo (o osobach ze specjalnymi potrzebami, w szczególności z ADD i ADHD)

\subsection{Analiza wyrażeń najczęściej stosowanych w języku polskim i an- gielskim}

\begin{tabular}{|l|l|}
\hline Język polski & Język angielski \\
\hline sprawny inaczej & differently abled \\
\hline & uniquely abled/ otherly abled \\
\hline & physically/mentally challenged \\
\hline niepełnosprawny & inconvenienced \\
\hline & disfranchised (e.g. physically, mentally) \\
\hline mający problem w uczeniu się & learning difficulties (ld) \\
\hline $\begin{array}{l}\text { reprezentujący specjalne potrzeby } \\
\text { edukacyjne }\end{array}$ & $\begin{array}{l}\text { representing special education needs (sen } \\
\text { students) }\end{array}$ \\
\hline syndrom/ zespół & syndrome \\
\hline niepełnosprawny & impaired (visually impaired) \\
\hline niedowidzący & hard of (seeing) \\
\hline niedosłyszący & hard of hearing \\
\hline mający problem z & having problems /difficulties with \\
\hline osoba z & person with \\
\hline osoby z innymi umiejętnościami & people with differeing abilities \\
\hline osoby z ograniczonymi osiagnięciami (?) & retarded in achievement \\
\hline
\end{tabular}




\begin{tabular}{|l|l|}
\hline $\begin{array}{l}\text { klasy integracyjne/zajęcia kompensa- } \\
\text { cyjne /wyrównawcze }\end{array}$ & $\begin{array}{l}\text { mixed ability classes / remedial classes/ } \\
\text { work/ support classes }\end{array}$ \\
\hline $\begin{array}{l}\text { klasy integracyjne w szkole podstawo- } \\
\text { wej / średniej }\end{array}$ & study center/academic workshop \\
\hline $\begin{array}{l}\text { niepełnosprawni /ludzie } \\
\text { niepełnosprawni }\end{array}$ & $\begin{array}{l}\text { disabled people/ people with disabili- } \\
\text { ties }\end{array}$ \\
\hline dobry/zły/słaby w... & good/poor/weak at \\
\hline upośledzony; ruchowo & retarded; physically impaired \\
\hline
\end{tabular}

\subsection{Podsumowanie}

Rzeźnicka-Krupa (2003: 87-88) podkreśla istotę języka adresowanego do osób z różnymi deficytami twierdząc, iż ,język jest podstawowym elementem procesów kategoryzacji jednostek i pełni liczne funkcje w procesie stereotypizacji, gdyż (...) konstruuje swoiste normy kulturowe, określające role społeczne osób przypisanych do danej kategorii społecznej". Jak obrazuja powyższe wyniki badań, obraz specjalnych potrzeb edukacyjnych a zwłaszcza język używany w kontekście edukacyjnym nie jest wolny od uprzedzeń czy też stygmatyzacji.

\section{BIBLIOGRAFIA}

Allan, K. and K. Burridge. 1991. Language Used As Shield and Weapon. New York: Oxford University Press.

Bańko, M. 2005. Stownik Peryfraz czyli myrażeń omownych. Warszawa: Wydawnictwo Naukowe PWN.

Dąbrowska, A. 1993. Eufemiżmy wspótczesnego jezyka polskiego. Wrocław: Wydawnictwo Uniwersytetu Wrocławskiego

Dąbrowska, A. 2005. Stownik Eufemizmón Polskich caylli w rzeçyy mocno, w sposobie lagodnie. Warszawa: Wydawnictwo Naukowe PWN.

Grodziński, E. 1980. Wypowiedzi performatywne. $Z$ ak.tualnych zagadnien filozofii jezylka. Warszawa: Wydawnictwo PWN.

Kita, M. 2005. Jesyykowe rytualy græecżnościowe. Katowice: Wyższa Szkoła Zarządzania Marketingowego i Języków Obcych w Katowicach.

Marcjanik, M. 2001. "Etykieta językowa" w Wspótczesny jezyy polski. Lublin: UMCS.

Marcjanik, M. 2007. Græecz̧nosí w komunikacji jeaykoowej. Warszawa: Wydawnictwo Naukowe PWN.

McMinn, J. 2006. Supporting Children with Speech and Language Impairment and Associated Difficulties. Continuum: London.

Krasowicz-Kupis,G. i K. Wiejak. 2008. Skala Inteligencji Wechslera dla Drieci (WISC-R) w Praktyce Psychologicznej. Warszawa: Wydawnictwo Naukowe PWN. 
Mazińska, M. 2004. Polityka Edukacyjna Unii Europejskiej. Warszawa: Wydawnictwa Szkolne i Pedagogiczne Spółka Akcyjna.

Rees, N. 1994. The Politically Correct Phrasebook. What they say you can and cannot say in the 1990s. London: Bloomsbury.

Rees, N. 2006. A Man about a Dog. Euphemisms \& Other Examples of Verbal Squeamishness. London: Harper Collins Publishers.

Rzeżnicka-Krupa J., "Językowy obraz niepełnosprawności (komunikat z badan̂)”. W: Integracja osób niepełnosprawnych, (red.) Kazanowski Z., Osik-Chudowolska D., Wyd. UMCS, Lublin 2003, 87-88.

Strong, J. and M. Flanagan. 2005. AD/HD For Dummies. Indianapolis: Wiley Publishing, Inc.

Waterhouse, S. 2000. A Positive Approach to Autism. London: Jessica Kingsley Publishers Ltd.

Woodford, K. and G. Jackson (eds. et. al.) 2003. Cambridge Advanced Learner's Dictionary. Version 1.0 on CD-Rom based on the printed edition of Cambridge Advanced Learner's Dictionary. Copenhagen: Cambridge University press.

\section{INNE:}

Smyth, B. "How do we meet the challenge of diversity?" in SCAN vol. 24 no.3 August 2005; http:/ / www.schools.nsw.edu.au/media/downloads/schoolsweb/ studentsupport/programs/disability/challenge.pdf DW 15.11.2007.

Ustawa z dnia 7 września 1991 r. o systemie oświaty (tekst jednolity Dz. U. z 1996 r., Nr 67, poz. 329 z późniejszymi zmianami

The Disability and Discrimination Act (1995)

Children Act (1989),

The Education Act (1996)

Special Education Needs Code of Practice (2001) 
